\title{
Optimising waste management assessment using fragmentation analysis technology
}

\author{
S Pearce Mine Environment Management Ltd, UK \\ D Brookshaw Caulmert Ltd, UK \\ S Mueller Boliden Mines, Sweden
}

A Barnes Geochemic Ltd, UK

\begin{abstract}
The blasting and excavation of rock at mine sites generates a heterogeneous waste/ore product with a wide range of particle sizes. The study of the particle size profile generated as a result of mining is typically termed 'fragmentation analysis'. Although the potential for material geochemical properties to vary with grain size as a result of the mining process has long been known, the concept is not commonly subject to detailed analysis. As a result, it is typical at the mine planning stage for both waste and ore materials to be represented within mine block models and schedules as comprising monolithic blocks with respect to geochemical properties. However, significant changes to material properties that do occur as a result of fragmentation have the potential to significantly alter both the environmental risk profile and economics of the proposed mine plan. This paper discusses the application of modern fragmentation analysis techniques to the characterisation, management and long-term planning of waste rock.

Detailed laboratory-based heterogeneity testing including geochemical, compositional and quantitative mineralogical analysis has been twinned with fragmentation data to assess properties of as-mined waste at two operational sites. The results presented herein highlight the importance of incorporating fragmentation analysis into the process of setting and validating cutoff grades for ore and waste, and in particular the management of low-grade ore. Opportunities are identified for recovery of resources that would otherwise have been discarded and removal of high-risk material from the waste rock stream. The results indicate that, at a high level, the use of a grade-weighted cutoff grade approach to waste modelling requires careful consideration before being relied upon to estimate environmental risks from mining. Further, the study indicates the benefits of the integration of a robust validation program into waste characterisation and grade control systems to both manage risk and optimise project economics.
\end{abstract}

Keywords: fragmentation analysis, mine planning, waste characterisation

\section{Introduction}

\subsection{Study rationale}

Typically, waste characterisation classification systems used as part of long-term mine planning based on industry best practice geochemistry methods (Garbarino et al. 2018; Price 2009) are translated into mine planning and operations by the utilisation of block models (Pearce et al. 2012). The majority of waste characterisation classification systems used as part of long-term mine planning utilise block models that define waste based on discrete grade-weighted cutoff grades (COGs). The COG is used to differentiate between waste and ore zones, and wastes of different geochemical or physical properties (Pearce et al. 2012). The use of a COG approach reflects an underlying assumption that waste rock properties can be defined and treated in block models as having static and bulk characteristics in the same manner as ore. That is to say that, once mined, the waste material block has the same intrinsic property as defined from the averaged value obtained from the block model. This assumption arises typically because it is resource 
geologists and mine planners that create the waste models using the same modelling and estimation approach as is used as part of ore block estimation. However, there is a key difference between how these assumptions affect planning decisions for ore and waste. With respect to ore blocks, any changes to material properties that occur after mining are not generally relevant as the material is blended, crushed and processed in bulk. In relation to waste blocks, however, changes in geochemical or physical properties after mining can be very significant with respect to environmental risk and management costs. A number of studies (e.g. Elghali et al. 2018; Pearce et al. 2014) have demonstrated the significance of particle size with respect to geochemical characterisation of as-mined wastes. A profiling tool that allows the quantitative assessment of the scalar and temporal effects of heterogeneity on geochemical classification by using particle size distribution (PSD)-dependent testing and statistical analysis was demonstrated by Pearce et al. (2014). Determination of the constitution heterogeneity and fundamental sampling error, for example, were outlined as key parameters that can be defined using profiling tools (but which are not typically considered in commonly used guidance documents; e.g. GARD Guide; The International Network for Acid Prevention [INAP] 2009).

In general, geochemical test work, which is used to form the basis of both ore and waste block models, utilises samples of geological drillcore for feed material. Although significant efforts are made to recover and analyse drillcore material samples from representative areas of different grade materials, the core material represents in situ rock that has not been subject to fragmentation from mining. As such, analyses results obtained from these samples can only be assumed to represent the 'average' properties of the host rock that has been drilled in situ.

Price (2009) notes in regard to geochemical waste characterisation that:

"Examples of a scientific approach in checking whether assumptions in material characterization are correct include periodically testing that samples of exploration drillcore or pre-blast drill cuttings have similar composition to waste rock fines."

The implication being that the effects of fragmentation should explicitly be accounted for in geochemical studies if a scientific approach is being adopted, although it is noted that this may not be possible until mining has started. Price further notes in this regard that:

"Prior to mining, it is difficult to predict the physical effects of excavation, processing and deposition on the chemical composition of different size fractions or areas of the waste, such as the $<2 \mathrm{~mm}$ fraction of waste rock."

Taking both of these statements together, it is apparent that while accounting for the effects of fragmentation on waste material geochemical properties may be difficult prior to mining, once mining begins it should be a priority. Indeed, once mining has commenced, it can be relatively straightforward to initiate a validation program that can assess the impacts of fragmentation on the current waste management and assessment program. This can be achieved by integrating fragmentation analysis into waste grade control programs, or acid and metalliferous drainage (AMD) validation sampling exercises.

\section{$2 \quad$ Fragmentation analysis}

\subsection{The fragmentation process}

During the mining process, blasting of ore and waste rock is designed and carried out to fracture the in situ rock mass to enable excavation and transport of the material. Run-of-mine (ROM) fragmentation is considered optimal when the material is fine enough and loose enough to ensure efficient excavation and loading operations. The blasting optimisation strategy is usually focused on minimising total mining costs and maintaining the optimal ROM fragmentation characteristics (Kanchibotla et al. 1999). Singh (2016) notes that:

"The goal of efficient blasting is determined by investigating the relationship between blast design parameters and fragmentation. It is extremely important to make the 
connection between rock blasting results and their impact on the downstream operations. It is well accepted that fragmentation has a critical effect on the loading operations, but little quantitative information is available, upon which rational blasting strategies can be outlined."

Although this reference is made with regard to downstream ore processing, it should be obvious that this statement would also apply to the consideration of the impact of the fragmentation profile on waste rock management aspects. For example, the environmental risks and resultant management costs of the waste rock generated will depend on the blasting strategy adopted. In general, there is not likely to be consideration of AMD risk in the cost model adopted for blasting strategies if fragmentation studies have not been completed. As such, this aspect likely represents a significant source of missed opportunities for optimised waste management planning at mine sites.

\subsection{Fragmentation analysis}

Fragmentation analysis is a common technique (e.g. Mohamed et al. 2019; Noy 2013) used as part of economic optimisation of mining projects. The analysis involves assessment of the PSD of mined material at various stages in the mining process, typically after blasting has occurred. The most utilised method to quantify fragmentation is the determination of the size distribution using digital imaging processing techniques. This method, being low cost and practical, is the second reliable method after sieve analysis. In this method, images acquired from excavators, haul trucks, conveyor belts, and so on, are delineated automatically by using digital image processing techniques, and size distribution of fragmented rocks is determined (Mohamed et al. 2019). In recent years, development and adoption of new automated imaging technology has significantly reduced the cost of carrying out the process; for this reason, more and better data can be gathered at lower cost. The technique is used to a great extent to assess blasting efficiency in ore zones, as the as-mined particle size of ore material is a critical input to processing efficiency and cost. The technique is also used in waste zones but mainly to determine blast efficiency as part of assessing blasting costs. Because particle size has long been known to be a critical factor in the assessment of AMD risk of waste materials, an opportunity was identified to explore the potential to utilise the technology to supplement the waste characterisation and management process.

\section{Cutoff grade assessment}

To differentiate between ore and waste in mine plans and block models, a numeric COG is often utilised that is applied throughout the model domain (in the case of an open pit mine, the pit shell) by the use of model estimation parameters. In many cases, ore zones may be further split into low-grade and high-grade designations and waste zones may be split into a number of classes based on AMD risk (Pearce et al. 2012). Figure 1 shows a generic sliding scale to highlight the simplistic relationship between COG and material designation. In this basic example, three zones are identified:

- Ore zone: all material that has a grade above a designated 'hard' cutoff value is considered ore and is sent for processing (i.e. crushing and milling); this material is sometimes referred to as high grade.

- Marginal area: material in this zone is of lower grade than ore and may be considered ore or waste depending on the economics of the mine at the time. In many cases, this material is termed lowgrade ore and typically is stockpiled on site until such time that it becomes economical to process. If the material is not processed by the end of the life of the mine, this material may be placed in waste storage facilities (as such, this material may equally be termed high-grade waste).

- Waste zone: material in this zone is very low grade and is considered waste. Even if project economics improve in the future and the COG is reduced, it is considered unlikely the COG will be reduced enough to include this material. The waste zone may be further divided into groups based on waste characterisation studies, such as potentially acid forming (PAF) or non-acid forming (NAF). 


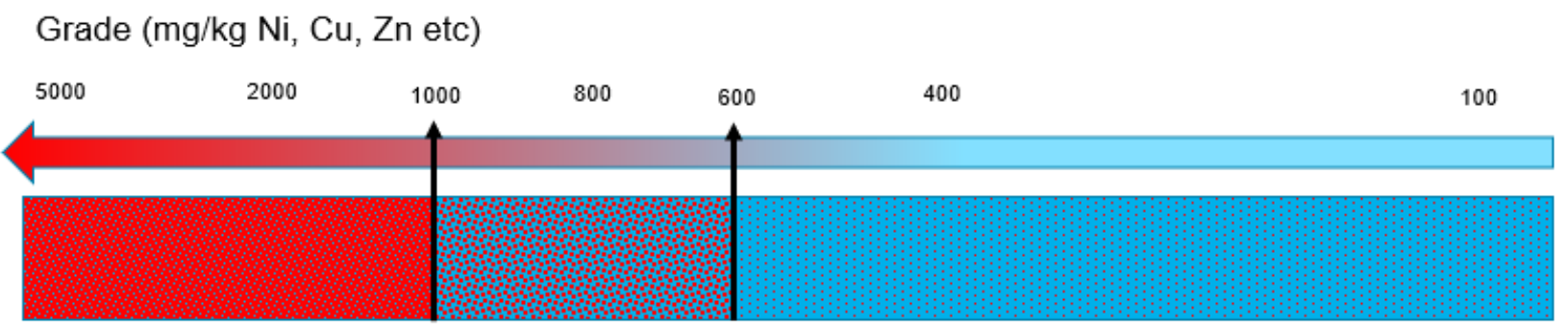

"Hard" Cut Off = Ore Marginal area $\quad$ Very low grade $=$ always waste

Figure 1 Sliding scale to represent use of cutoff grades in definition of waste and ore

Within the 'waste zone', waste classification systems are used that are generally based on the predicted risk of AMD based on global guidance documents such as MEND (Price 2009) and the GARD Guide (INAP 2009). These systems often use categories that have been 'bookended' into broad 'catch-all' definitions such as PAF or NAF categories. With respect to economic assessment, this approach typically assigns no economic 'value' (negative or positive) to waste blocks irrespective of classification other than to consider load and haul costs for disposal. This lack of cost modelling is driven by the assumption that waste has no intrinsic value (i.e. the material has no resource recovery potential or other utility). Further, that costs of managing waste are adequately accounted for by implementation of generic waste management plans. The adoption of these broad assumptions as part of typical waste management strategies is, in many cases, considered to reflect current best practice (Garbarino et al. 2018) given they are based on standardised and established mining approaches. The implication is that these approaches are considered to be adequate to capture risk and provide an optimised cost model for waste management. However, as has been indicated, the effects of fragmentation are not commonly incorporated as part of the waste classification system development, and for this reason, there may be an opportunity to reappraise the cost model.

\section{$4 \quad$ Results}

\subsection{Fragmentation data}

The PSD profiles for three waste types from an operational open pit base-metal mine site were collected between June 2016 and October 2017. The fragmentation analysis was carried out using automated Orica cameras fitted to two shovels operating onsite during this period. Recorded data were linked with the corresponding blast, material block and material type by following the progress of the shovels daily. Approximately 32,000 images of blasted waste rock from 178 blasting events were processed and analysed (Figure 2). The PSD profiles of the three waste types are very similar to each other, indicating that blasting produces a consistent waste material product with respect to particle size, which is independent of waste type. It is important to note that the fine fraction accounts for a relatively small proportion of the overall waste mass, with $<20 \%$ mass being $<10 \mathrm{~cm}$ diameter. 


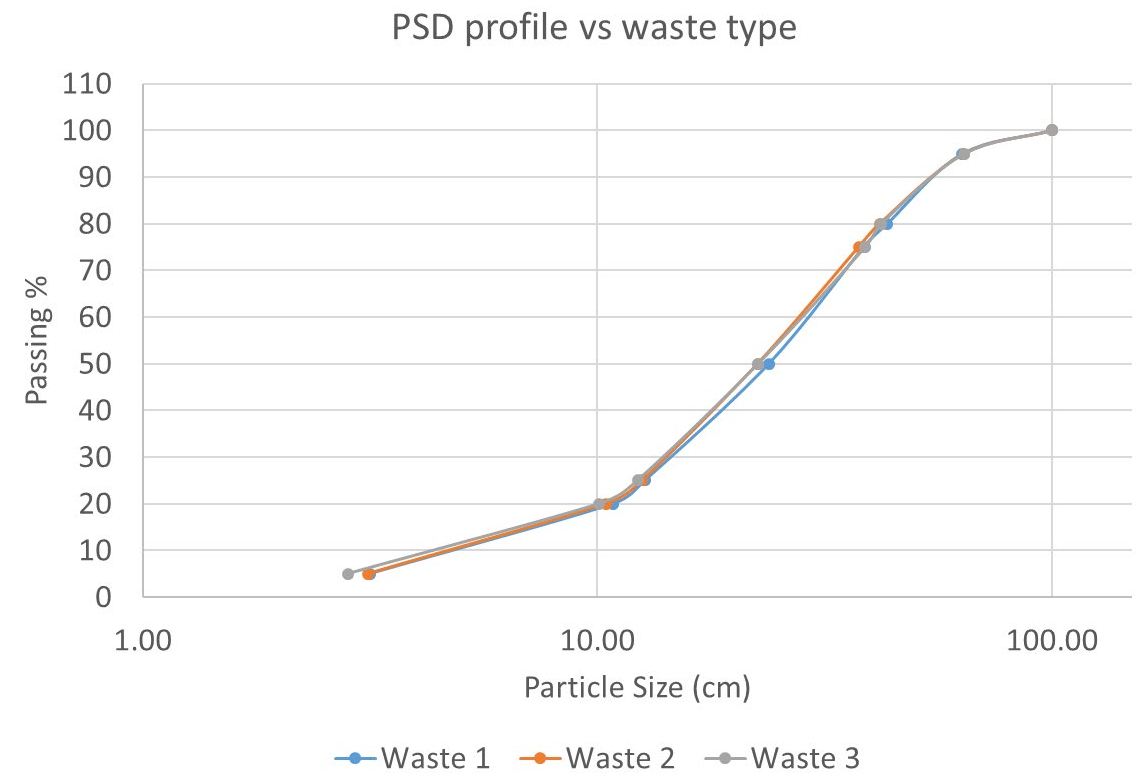

Figure 2 Particle size distribution curve for three waste material types based on data collected from 178 blasting events

Once the fragmentation profile for the blasted waste rock had been established, laboratory assessment of key particle size fractions was carried out to include compositional and mineralogical analysis.

\subsection{Sulphide speciation based on particle size}

Based on extensive geochemical and mineralogical characterisation data, the waste material at the site can be characterised as comprising a relatively homogenous ultramafic mineralogy (tremolite, olivine, clinopyroxene) with low-grade ( $<2 \%$ weight) sulphides (pyrrhotite, pentlandite, chalcopyrite) and carbonate (dolomite and calcite) minerals ( $<0.5 \%$ weight). Nickel is hosted within both sulphides (pentlandite) and silicates (mainly olivine), with mineralogical analysis including scanning electron microscope (SEM) indicating around $400 \mathrm{ppm}$ may be hosted in silicates. Copper is found almost exclusively (>95\%) in the sulphide phase chalcopyrite. The dominant sulphide mineral is the iron sulphide pyrrhotite.

To provide an indication of the effect of fragmentation on the geochemical properties of waste from the site (for which the PSD data in Figure 2 have been provided), seven bulk waste rock samples were selected for compositional analysis. The samples ( $2-5 \mathrm{~kg}$ weight) were obtained from sonic drillcore material (from a subset of $\sim 100$ samples) that was collected as part of a drilling program into existing waste rock storage facility. The drillcore material is considered to be broadly representative of waste rock properties given that the drilling method produces relatively 'undisturbed' samples. Basic PSD analysis was undertaken on the drillcore samples with dry sieving to determine the $<2.3 \mathrm{~mm}, 2.3-22 \mathrm{~mm}$ and $>22 \mathrm{~mm}$ fractions. The profiles of the drillcore samples analysed were compared to the waste rock fragmentation data to confirm a similar distribution.

The seven samples were all subject to the same preparation and analysis process:

- Samples were split (using dry sieving) into three subsamples based on grain size fractions: $<2.3 \mathrm{~mm}$, 2.3-22 $\mathrm{mm}$ and $>22 \mathrm{~mm}$.

- Each subsample was then split using a riffle splitter and a $500 \mathrm{~g}$ subsample was then pulverised.

- A four-acid digestion of the pulp sample was carried out to allow for compositional analysis (inductively coupled plasma [ICP] analysis carried out by the ALS laboratory Ireland). 
Elemental analysis was completed at ALS Geochemistry Ltd. The samples were analysed using inductively coupled plasma mass spectrometry (ICP-MS) in coalition with a four-acid digestion; the method is standardised at ALS with the method code ME-MS61L. The samples were analysed for a 48-element suite with acid digestion used to enhance detection limits through dissolution of minerals, reducing oxide formation to $<0.5 \%$.

A total of 21 samples were analysed (seven samples each split into three subsamples). The results of the analysis are shown in Figure 3, which presents the data as a box and whisker plot. The results indicate that the finest fraction of the samples $(<2.36 \mathrm{~mm})$ has a notably higher concentration of both nickel and copper compared to the $>22 \mathrm{~mm}$ fraction.

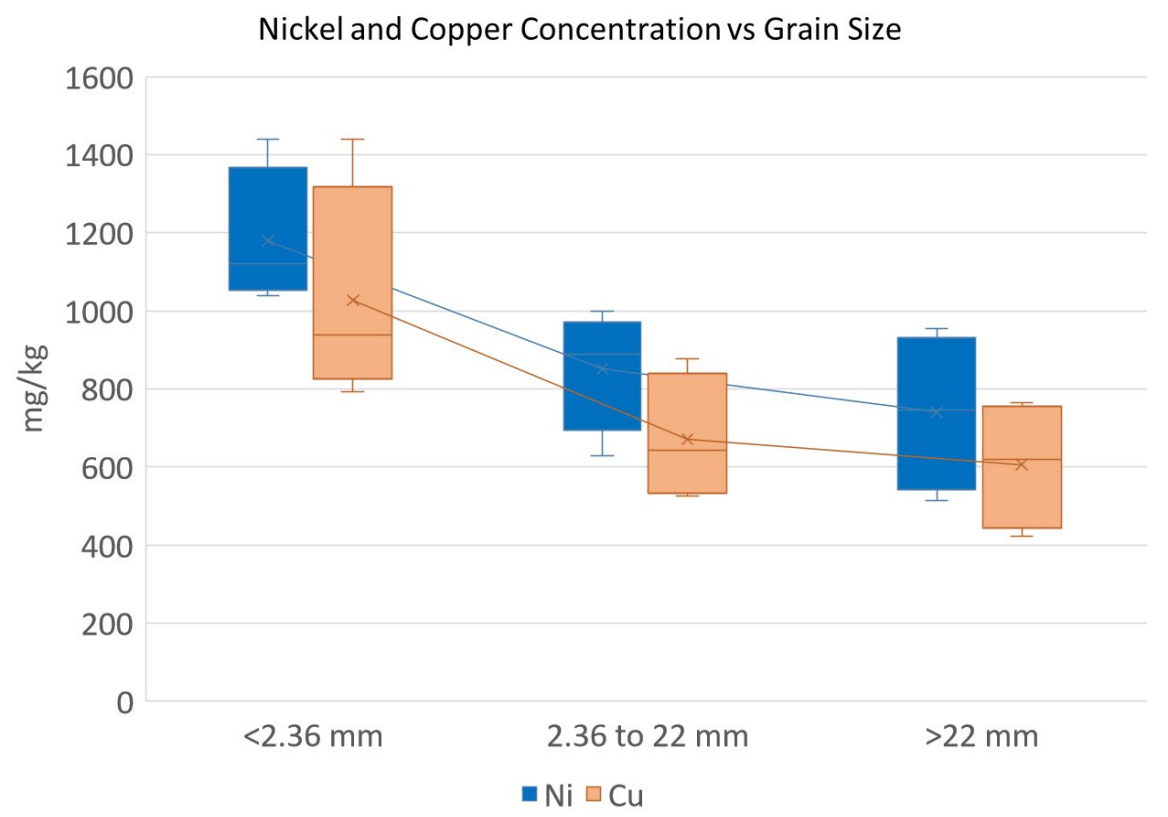

Figure 3 Nickel and copper concentration by particle size fraction

Figure 4 shows the results of the copper and nickel analysis plotted as an upgrade percentage, which represents the relative increase in grade between the $<2.3 \mathrm{~mm}$ and $>22 \mathrm{~mm}$ fractions.

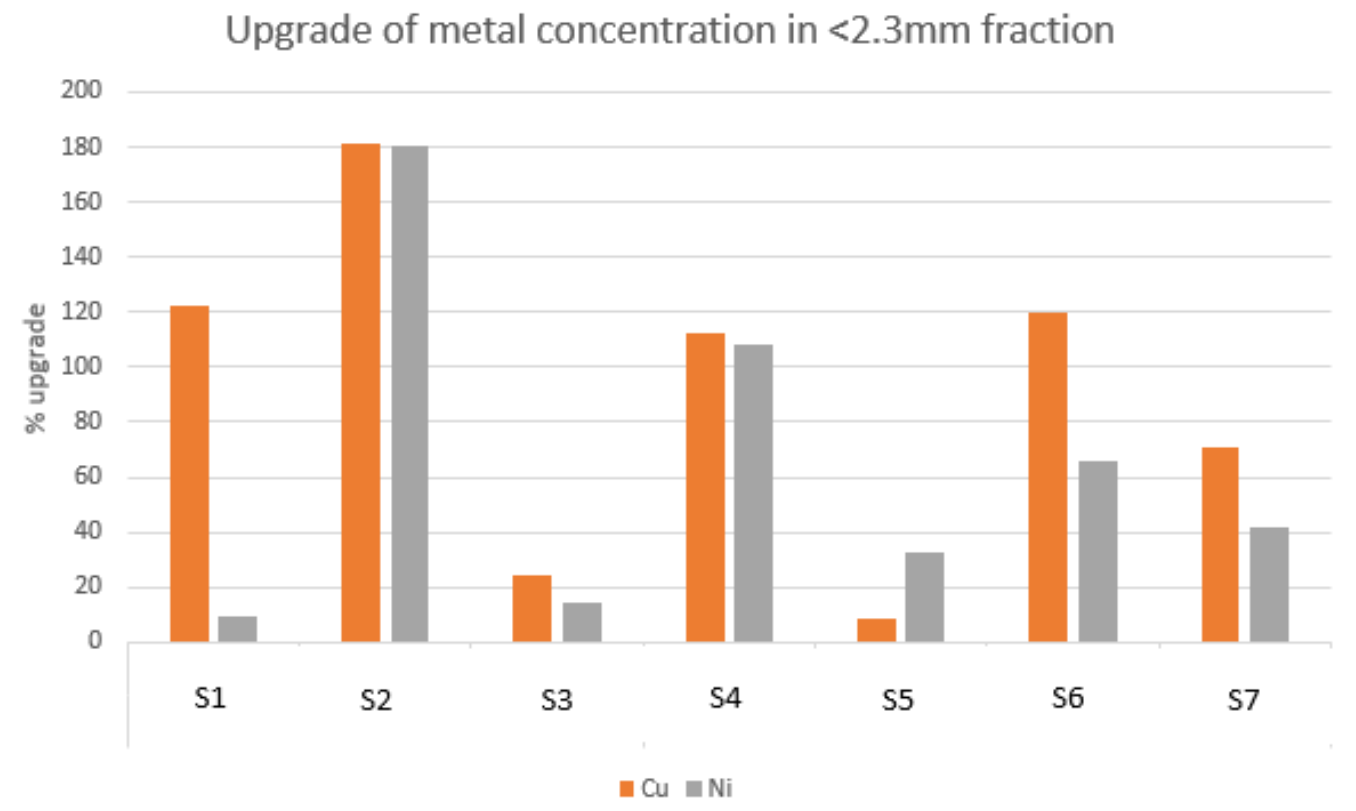

Figure 4 Nickel and copper upgrade ( $<2.3 \mathrm{~mm}$ versus $>22 \mathrm{~mm}$ fraction) 
To provide additional data on the mineralogical variation that may be causing the concentration of nickel and copper in the finer grain size fractions, mineralogical analysis was then carried out by Petrolab Ltd. One sample of the $<2.36 \mathrm{~mm}$ size fraction and one sample of the $>22 \mathrm{~mm}$ size fraction were analysed using SEM. A polished block was prepared from each of the submitted sample fractions and carbon coated to a thickness of $10 \mathrm{~nm}$. Each block was analysed using a ZEISS EVO MA 25 SEM fitted with a Bruker XFlash 6|60 X-ray detector for energy-dispersive X-ray spectroscopy (EDX) analysis. The Mineralogic Mining 1.5 software controlled the SEM and acquired morphology and X-ray data. The results of the analysis are shown in Table 1.

Table 1 Selected mineralogy based on particle size from SEM EDX data

\begin{tabular}{lll}
\hline Mineral phase & $<\mathbf{2 . 3 6} \mathbf{m m}$ & $>\mathbf{2 2} \mathbf{~ m m}$ \\
\hline Pentlandite & $0.16 \%$ & $0.03 \%$ \\
Chalcopyrite & $0.2 \%$ & $0.06 \%$ \\
Dolomite & $0.44 \%$ & $0.08 \%$ \\
\hline
\end{tabular}

Results in Table 1 indicate that higher concentrations of nickel-bearing pentlandite and copper-bearing chalcopyrite were reported for the $<2.36 \mathrm{~mm}$ fraction. This fraction is where highest concentrations of these metals were recorded from chemical analysis (Figure 3). Figure 5 shows the results of electron probe microanalyser (EPMA) analysis of the samples given in Table 1. The deportment of nickel is noted to be significantly higher to the pentlandite phase in the $<2.36 \mathrm{~mm}$ fraction compared to the $>22 \mathrm{~mm}$ fraction. In the $>22 \mathrm{~mm}$ fraction, nickel deportment is mostly to the silicate phase. These data further support the conjecture that pentlandite is preferentially concentrated in the finer fraction phase, which is responsible for the increased nickel content. The deportment of nickel and copper to sulphide and silicate phases is important with respect to both the potential for metal recovery (ore/waste COGs are based on nickel/copper sulphide content) and AMD risk (as metal sulphides present the majority of metal release potential).

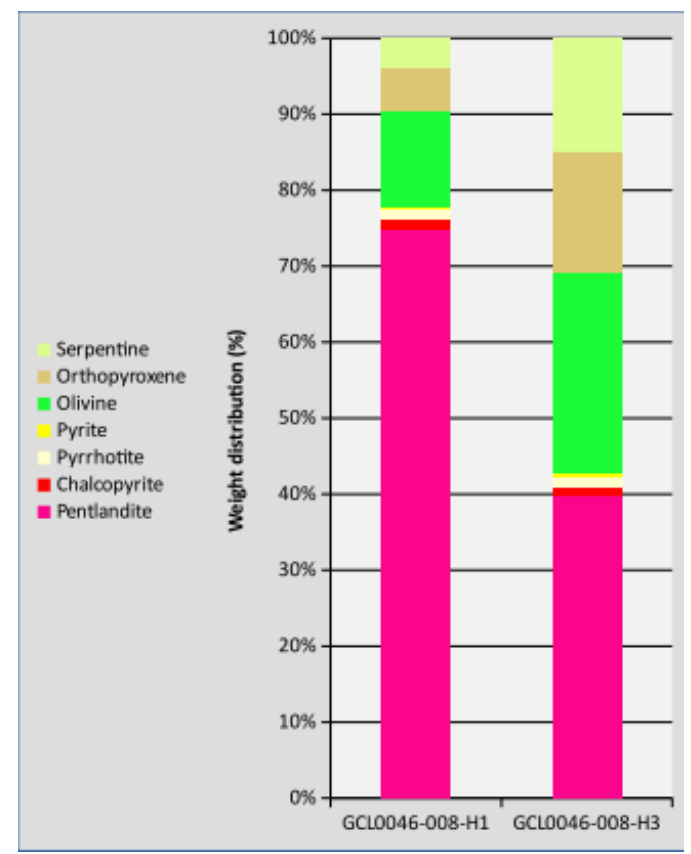

Figure 5 Nickel deportment by sample from EPMA ( $\mathrm{H} 1=<2.36 \mathrm{~mm}$ sample, $\mathrm{H} 3=>22 \mathrm{~mm}$ sample)

The results provided in Figures 3-5 indicate that blasting-related fragmentation may significantly concentrate nickel and copper sulphides in the finer fraction both in an absolute term and relative to pyrrhotite. The likely driver of this concentration effect is considered to be related to the presence of nickel/copper-bearing sulphides in veins/fracture fills (rather than presence as broad disseminations). Blasting would tend to result in fractures forming along weaknesses, which would include any vein/fracture fill zones. 
Figure 6 shows the ratio of nickel to iron in the samples. It is clear that the nickel-to-iron ratio is much higher in the samples that show upgrade of nickel (i.e. the finer fractions). The results indicate that the pentlandite-to-pyrrhotite ratio is likely increasing as grain size decreases. It is noted that COGs for ore and waste at the site are defined based on nickel/copper sulphide content, as processing is only effective at recovering metals from sulphide content not silicate fraction. The significantly higher nickel and copper sulphide grades in the $<2.36 \mathrm{~mm}$ fraction mean that this material may be classified as ore and not waste. As such, an opportunity for nickel and copper recovery from 'waste' materials can be envisaged. The potential for recovery is high because this material could be relatively easily separated using basic screening technology and processed as ore. The higher copper/nickel sulphide content relative to pyrrhotite and fine grain size both enhance the potential processing/recovery efficiency and lower cost burdens. For example, ore materials are required to undergo primary and secondary crushing prior to milling. However, the $<2.33 \mathrm{~mm}$ fraction material could be sent direct to the mill if it can be separated from the waste mass. The reduced pyrrhotite content may also be a benefit with regard to processing, as this may increase the efficiency of the flotation circuit. In practical terms, the recovery of the nickel/copper would require the establishment of a large-scale mobile screening plant in the pit or a fixed plant outside the pit area to remove the higher metal containing fine fractions of the waste. It is noted, however, that because block modelling and grade control activities are carried out at the site, along with fragmentation analysis, screening activities could be targeted on certain areas of the waste. Zones of waste where copper and nickel grades are known to be higher from block models can be targeted to reduce the amount of waste requiring processing and increase potential grades of recovered material. This may make in-pit screening a viable option.

The upgrading of nickel/copper sulphide content in the fine fraction also has potentially significant implications for AMD risk assessment and management. The higher surface areas and higher sulphide content of the fine fraction can result in these fractions having the highest relative AMD risk (Elghali et al. 2018). This result is important to consider as the concentration of nickel and copper sulphides in the finer fraction will increase the potential for metalliferous production relative to the assumed characteristics of the 'bulk' material properties. This is because the relative ratio of nickel and copper sulphides to iron sulphides will dictate the concentration of nickel and copper in seepages from oxidised waste materials.

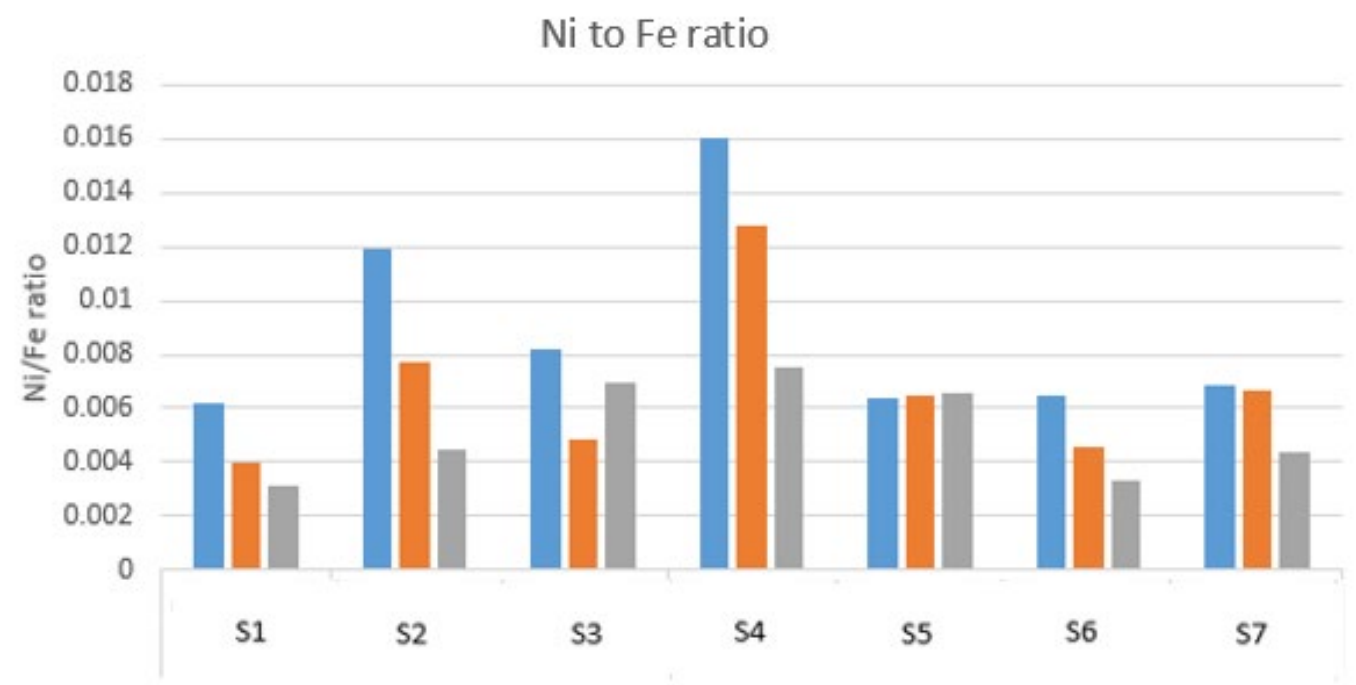

Figure 6 Nickel-to-iron ratio indicating relative concentration of pentlandite to pyrrhotite

The finer fractions will have both higher weight-for-weight grade of copper and nickel but also higher pentlandite/chalcopyrite-to-pyrrhotite ratios. However, conversely, because copper/nickel sulphides are concentrated in the fines, the coarser materials will have a significantly lower AMD risk profile (lower copper/nickel sulphide grade and smaller relative surface area). As such, an opportunity can be identified to reclassify material that may have been classified in the block model as having a higher risk with respect to AMD formation. This may be achieved by targeted screening out of the higher-risk fines and leaving the 
lower-risk coarse materials. Alternatively, this may be achieved by optimising blasting practices during mining to reduce fines generation in targeted areas so as to have a significantly lower risk profile.

These results taken together highlight an opportunity to significantly optimise waste management procedure and reduce waste management costs. The bulk of the material classified as high risk in the waste model and schedule can potentially be reclassified as lower risk. This could be practically achieved if the low-risk coarse fraction material can be separated from the higher-risk fines, which can then be potentially sent direct to processing to recover the valuable base-metal content. Sending the fines to the process will achieve two benefits: that recovery of economic metal sulphide content may provide an economic return and that the high-risk AMD source has been removed from the waste rock storage facility. By sending the fines through the process the waste product ultimately ends up being sent to tailings facilities. Relative to mixing and placement of the sulphidic fines waste in waste rock dumps dominated by coarse materials (and high air flux), the placement in tailings dam has the potential to be a better solution to manage AMD risks (given the buffering potential provided by carbonates present and lower potential for oxygen ingress).

To determine the potential for the release of AMD from each size fraction, static leaching tests were carried out on four of the samples. The tests involved $24 \mathrm{hr}$ static leaching process using deionised water as the extractant and were carried out at a liquid-to-solid ratio of 2:1. The liquor was then filtered and analysed at ALS (Ireland) for $\mathrm{pH}$ and electrical conductivity along with metals by inductively coupled plasma optical emission spectrometry (ICP OES) and major cations/ions including sulphur. Figure 7 shows sulphur release from the 2:1 leach tests. It is noted that the materials are partially weathered as a result of exposure from a number of years of storage. As such, they have secondary sulphate minerals present that are highly soluble (gypsum and epsonite). It is noted from the results that the $>22 \mathrm{~mm}$ fraction produces little if any sulphate compared to the finer fractions, and the $<2.36 \mathrm{~mm}$ fraction has significantly higher sulphur release. This significantly lower sulphur release in the coarser fraction is linked to lower levels of sulphide reactivity. The results likely reflect the lower reactive mineral surface area, resulting in the significantly lower AMD risk profile of this material. The results confirm the significantly higher risk of AMD presented by the $<2.3 \mathrm{~mm}$ fraction.

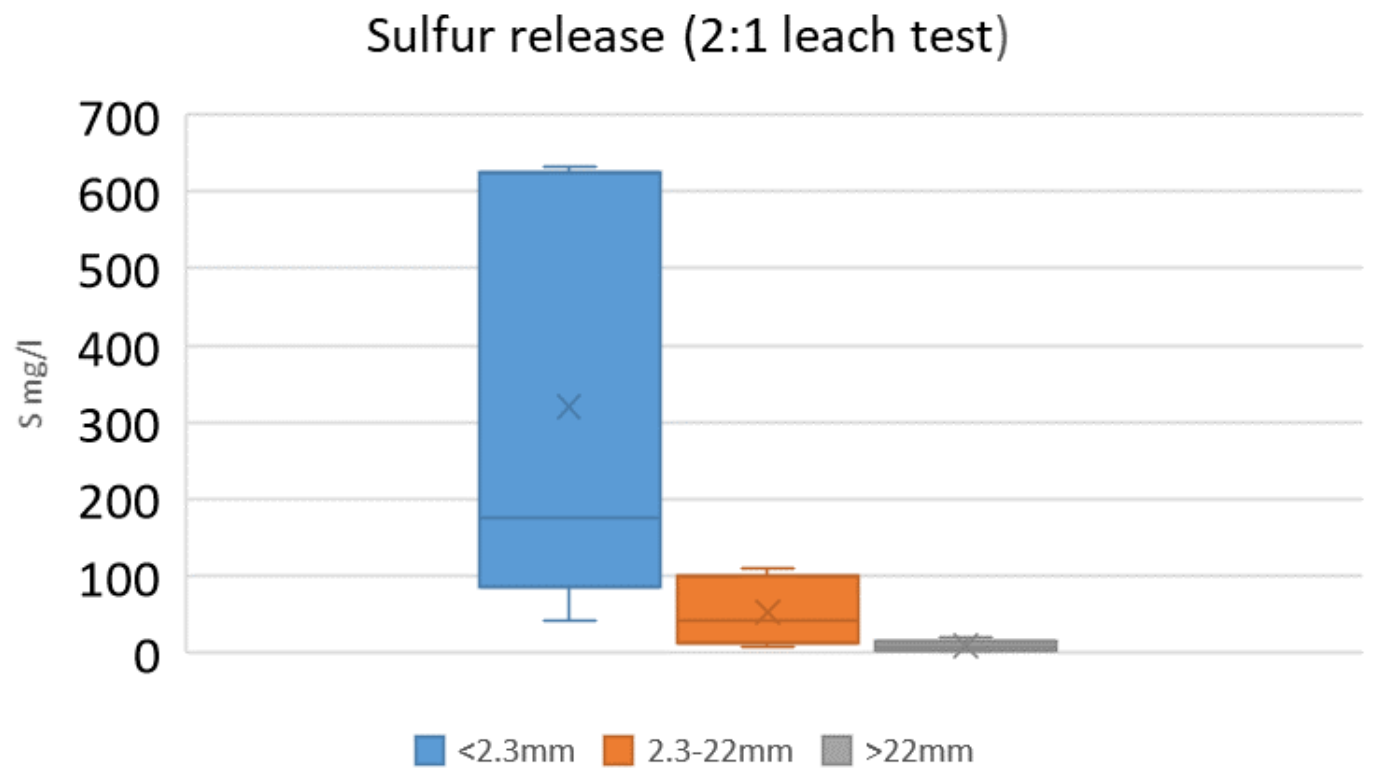

Figure 7 Sulphur release from 2:1 leach test (based on particle size)

\subsection{Carbonate speciation}

Results from mineralogical analysis shown in Table 1 indicate that the carbonate dolomite is also concentrated in the $<2.36 \mathrm{~mm}$ fraction. This observation is important as the presence of carbonates in mine waste in the finer fraction is a key factor in AMD risk mitigation. Buffering of acidity generation by carbonate 
minerals is most significantly influenced by the finer particle size fractions. This is because the finer fractions have higher surface areas and thus carbonate mineral reactivity rates are orders of magnitude higher.

To assess the distribution of carbonates, analysis of inorganic carbon (based on mineralogical analysis, inorganic carbon is considered to be an adequate proxy for carbonate content) was carried out on all of the samples analysed for sulphides. Figure 8 shows the results of inorganic carbon analysis. The carbonates appear to concentrate in the $2.36-22 \mathrm{~mm}$ fraction as well as the $<2.36 \mathrm{~mm}$ fraction. The $>22 \mathrm{~mm}$ fraction has a much tighter range and values are very low indicating that the $>22 \mathrm{~mm}$ fraction is almost devoid of carbonates. The results suggest that the source of carbonates is vein/fracture fillings/coatings that are liberated by blasting given the consistently low concentration in the $>22 \mathrm{~m}$ fraction. The results suggest that the concentrating of carbonates in the finer fraction will significantly increase potential buffering potential relative to the 'bulk' properties. This observation is important because the finer fractions $(<22 \mathrm{~mm})$ typically dominate porewater chemistry as a result of greater surface areas, and thus contact with pore waters. As such, dissolution rates (and thus buffering potential) for carbonates in the fine fraction has the potential to be orders of magnitude higher than the coarser fraction.

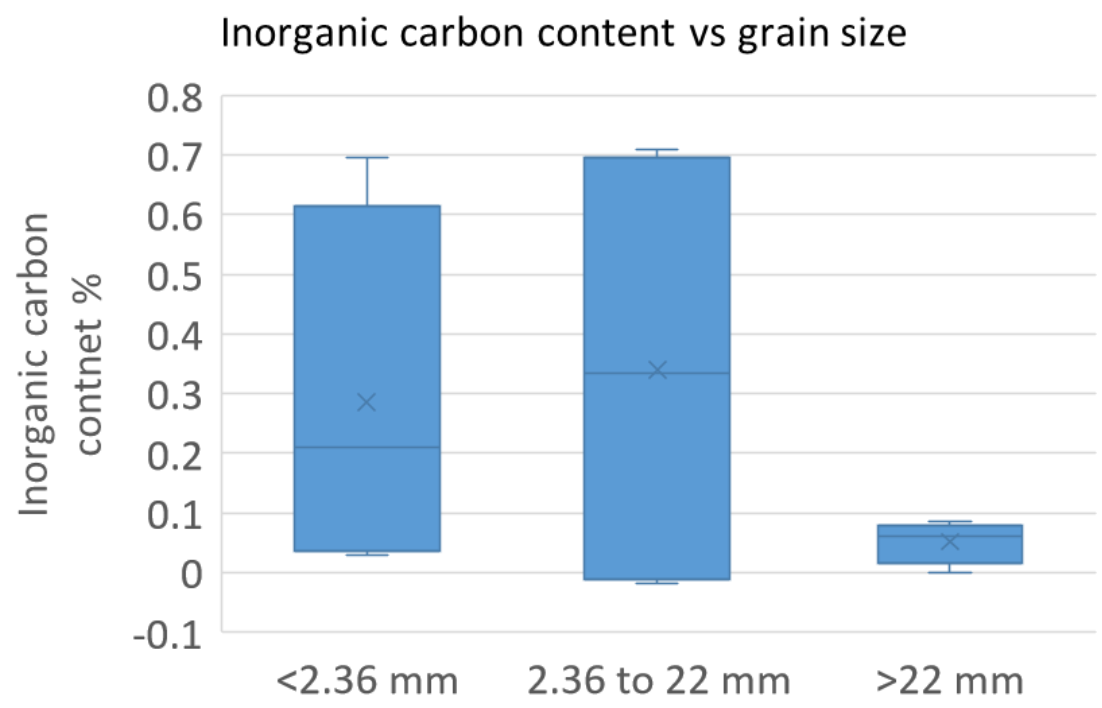

Figure 8 Carbonate carbon content based on particle size

To further evaluate buffering capacity, acid base characterisation curve (ABCC) tests (method as per AMIRA; Ian Wark Research Institute \& Environmental Geochemistry International 2002) were carried out on the same samples that inorganic carbon analysis was completed on. Figure 9 shows the results of ABCC tests carried out on the different fractions of waste material (with the titration step of $\mathrm{pH} 4.5$ shown). It is clear that the coarser fraction (>22 $\mathrm{mm}$ ) has significantly lower buffering capacity and the $<22 \mathrm{~mm}$ fractions have higher buffering capacity. These data directly support the implied higher potential for carbonate buffering in the $<22 \mathrm{~m}$ fractions noted in Figure 8 . 


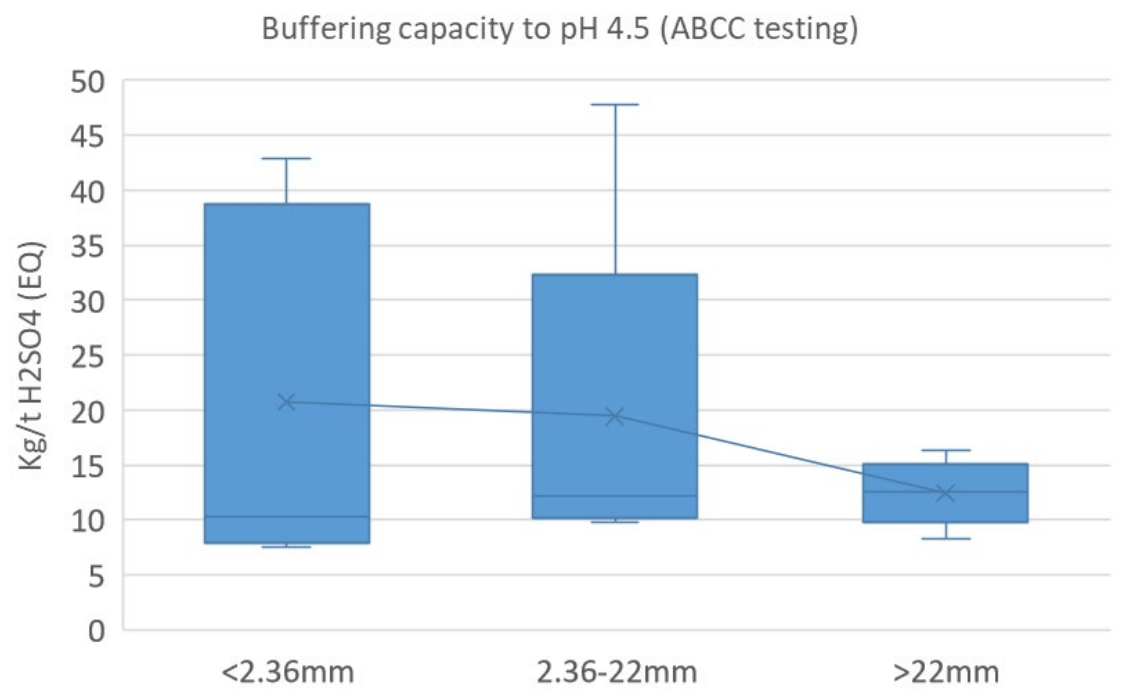

Figure 9 Buffering capacity to $\mathrm{pH} 4.5$ based on particle size (from $A B C C$ test)

In general, the results from Figures 8 and 9 indicate an opportunity can be identified to utilise materials that have high carbonate content and low metal sulphide content (produced from screening the $<22 \mathrm{~mm}$ fraction). This high carbonate low sulphide material may have uses such as alkalinity producing cover, source material for 'limestone' drains, source material for alkaline material to 'blend' with higher-risk material, and so on. The value realised from the production of an AMD management product would depend on assessment of the economics of producing such a product. Strategies such as optimising blast patterns to achieve higher fragmentation and higher fines content or screening suitable waste zones could be considered. Even if the material was not screened, the fact that the carbonates concentrate into the finer fraction means that these materials are likely to offer significantly higher buffering capacity than would otherwise be assumed in the block model.

\section{$5 \quad$ Visual assessment}

Although fragmentation analysis can be carried out using automated analysis technology, in many cases, visual assessment of rock types in the mine pit alone can provide important indications of likely fragmentation potential and behaviour. Figure 10 shows a close-up of a fresh sample of sulphidic material (post blasting) from a waste zone blast face obtained from a gold mine by the author. The material is from an area classified as low grade in the block model. The 'low-grade' designation arises because sulphidic material is found as a thin band of conglomerate material that displays pyrite infilling cavities within otherwise 'barren' massive and competent sandstone. The sample clearly shows 'loss' of sulphides from the cavity fillings as a result of blasting. This loss has occurred because the sulphide mineral texture is fine-grained and friable, and as such, blasting and mining causes the sulphides to disintegrate from the host rock and report to fine fraction. As a result of fragmentation, the competent sulphide-free silica-rich material will form the larger block sizes while the softer, less competent pyritic material will report to the finer fraction. The loss of sulphides is enhanced by the fine, poorly crystalline texture of the pyrite mineral texture. AMD risks may therefore be underestimated in these types of materials that have been classified in bulk from block models. This is because although bulk sulphide grades do not change as a result of fragmentation, the relative concentration of sulphides in the more reactive finer fraction is significantly increased. 


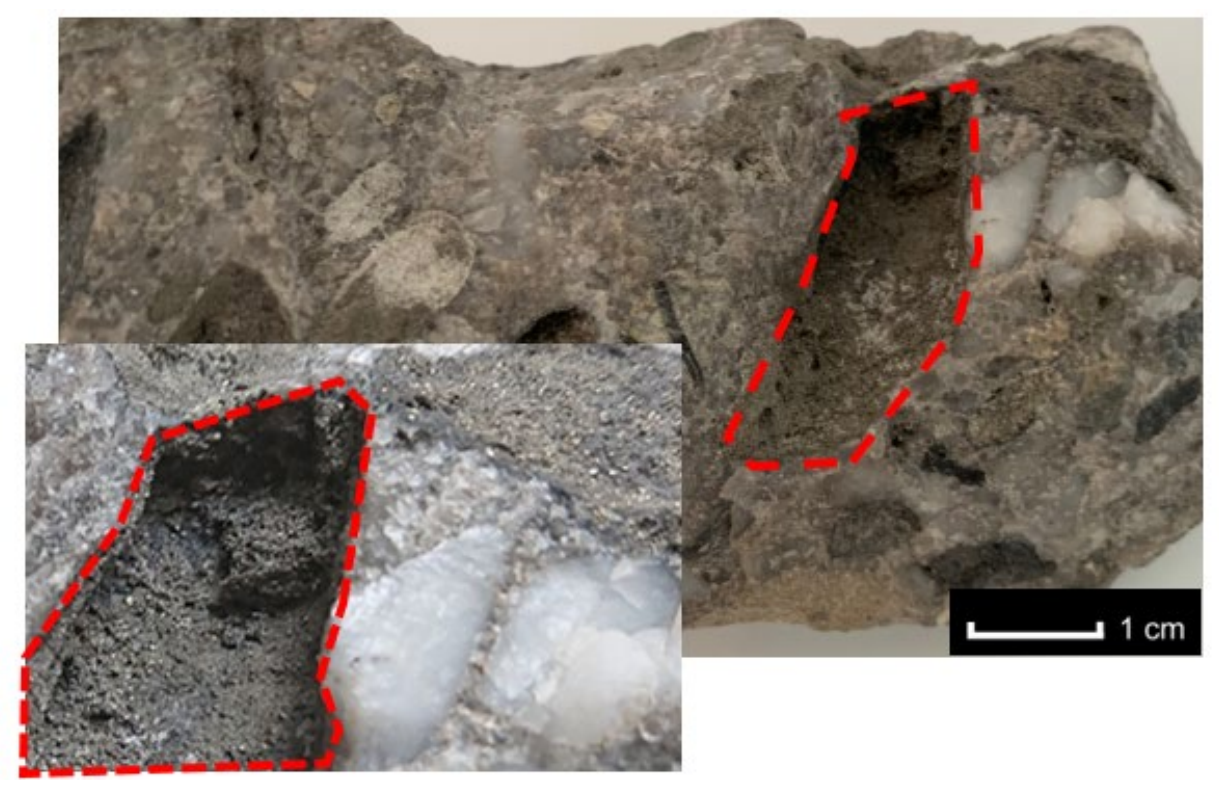

Figure 10 Rock sample (close-up) post blast showing friable/fine-grained sulphides 'removed' from cavity filings

\section{Implications for mine planning}

Fragmentation-based analysis has been carried out on a number of samples of as-mined waste and involved assessment of the compositional and mineralogical content across different grain size fractions. The results indicate that fragmentation causes concentration of nickel/copper sulphides and carbonates into finer grain size fractions. It has been found that the geochemical properties of the waste, as mined, does not consistently represent the bulk composition or properties of the waste determined by block models developed from analysis of drillcore samples.

It is noted that other studies (Elghali et al. 2018; Pearce et al. 2014) have indicated similar findings from other sites, and as a result, it is likely that this phenomena may occur at many other mine sites with sulphide and carbonate mineralogy. Each site is different and the results herein should not be extrapolated directly; however, the findings indicate that fragmentation-based studies may be worthwhile completing to determine if opportunities to optimise waste management can be identified.

Key findings of the assessment are that (for the study site):

1. Mineralogical changes as a result of the blasting and mining process may reduce the risk of metalliferous drainage from larger particle sizes $(>22 \mathrm{~mm})$ due to reduced nickel/copper sulphide content and smaller reactive surface areas. In the mine model these materials may be classified as having high AMD risk (based on bulk properties). As such, a large potential cost saving could be identified if a means to separate this fraction out can be identified. Separation may allow the material to be reclassified as lower-risk material such that it no longer needs management as highrisk material. A reduction in volume of high-risk material may provide significant savings from reduction of engineering containment costs and also assumed future liability costs (closure risks).

2. Fragmentation causes carbonates to concentrate in the finer particle sizes, which means that buffering potential may be higher relative to that assumed from the bulk properties assigned in the block model. This is because there is an increase in the mass of available buffering minerals in the more reactive finer fractions. Value creation may be identified from the potential to generate an acid buffering material, which could be created by screening this fraction. This may be given a positive economic value in the mine model as this material has benefits for use in AMD management and may replace material that would otherwise have been imported to the site. 
3. Fragmentation causes significant upgrading in nickel/copper sulphide content in finer fractions, meaning that grades of these economic metals move closer to that of ore than waste. Because processing efficiency is driven by nickel/copper sulphide content, and because the material already has a finer grain size (less requirement for crushing and screening), there is an opportunity for this material to be separated and processed. The stream may represent a source of recoverable metals.

4. Concentration of nickel/copper sulphides into the finer grain size means that AMD risk may be underestimated by standard block modelling approach. This is because the model uses grade-weighted COGs to determine waste class. This in turn is based on the relative reactivity of materials from laboratory testing at specific sulphide grades and at specific ratios of iron sulphides to base-metal sulphides. Given that the finer fraction has both higher sulphide content and a higher ratio of nickel/copper sulphide to iron sulphide, then potential AMD risks may be higher than the block model indicates for certain waste zones.

5. The separation and processing of the finer fraction with higher metal content would, as well as metal recovery potential, also present an opportunity to significantly reduce project AMD risk. This is because the finer fraction with higher nickel/copper sulphide fraction comprises the majority $(>80 \%)$ of the potential total AMD risk from bulk mine waste mass. Processing of the material allows both removal of metals into product that will be sold offsite, and also the removal of the sulphide content from the waste rock dump stream where management of sulphide oxidation is challenging. The material may instead be directed to tailings waste stream. This may be significant from both cost and risk perspective as direction to tailings can potentially offer additional AMD management opportunities. Deposition in the tailings stream offers potential for lower oxygen ingress rates, higher saturation levels, and higher silicate/carbonate reactive mineral surface areas.

6. The use of fragmentation analysis to guide blasting patterns in waste zones may provide benefits, as the physical properties of the waste product can be controlled at the source. Blasting could be tailored to produce a finer or coarser waste product that may allow some control over AMD risk, and may provide opportunities to recover both metals and carbonates that may provide positive cost benefits.

\section{Conclusion}

The widespread use of block models as part of waste management for mining operations in recent times is recognised as representing an important step forward in improving waste management planning, AMD risk reduction and project cost optimisation. However, the findings of this research demonstrate that the approach should be viewed with caution. Classifying materials based on bulk grade-weighted averages without validating the approach by assessing the actual properties of the as-mined waste product may result in lost opportunities to optimise waste management practice. The consideration of the properties of waste and ore materials as 'fixed' within waste models and reliance on general COGs may therefore not be valid assumptions in all cases.

Fragmentation analysis has been identified as a potential means to assess the relative change to AMD risk profile of waste as a result of mining and opportunities to recover resources. New technology allows for in situ assessment of fragmentation during the mining process. This means that optimising the blasting process itself or implementing screening technology may realistically be used to 'change' the AMD risk profile of the waste product. Material designated as 'high risk' may be reclassified if the fragmentation profile can be biased towards coarser particle sizes, or if coarser material can be screened out. Further, this study demonstrates that opportunities to improve project economics can be identified using fragmentation analysis. This is because the recovery potential of potentially economic metals from material previously classified as 'waste' can be identified along with recovery of carbonates that may have 'value' onsite for use as part of risk mitigation strategies.

An opportunity for increased collaboration between mining geologists carrying out the block modelling and geochemists carrying out waste classification assessments can also be identified. Typically, mine geologists 
do not receive training in advanced waste characterisation assessment and geochemists are not trained to carry out block modelling. As such, without strong interaction there is significant potential for models to be produced in which neither the geochemist nor mine geologist may fully understand the potential risks introduced as a result of the modelling process. A more integrated approach to the modelling of waste would allow for these risks to be managed and all opportunities to optimise waste management approach to be identified.

\section{Acknowledgement}

The authors of this study acknowledge and thank Boliden mines for their cooperation throughout this study as well as the financial backing that was needed to make the study possible.

\section{References}

Elghali, A, Benzaazoua, M, Bouzahzah, H, Bussière, B \& Villarraga-Gómez, H 2018, 'Determination of the available acid-generating potential of waste rock, part I: mineralogical approach', Applied Geochemistry, vol. 99, pp. 31-41.

Ian Wark Research Institute \& Environmental Geochemistry International 2002, ARD Test Handbook: AMIRA P387A Project: Prediction and Kinetic Control of Acid Mine Drainage, AMIRA International, Melbourne.

Kanchibotla, SS, Valery, W \& Morrell, S 1999, 'Modelling fines in blast fragmentation and its impact on crushing and grinding', Explo'99: a Conference on Rock Breaking, The Australasian Institute of Mining and Metallurgy, Melbourne.

Mohamed, F, Riadh, B, Abderazzak, S, Radouane, N \& Ibsa, T 2019, 'Distribution analysis of rock fragments size based on the digital image processing and the Kuz-Ram model Cas of Jebel Medjounes Quarry', Aspects in Mining \& Mineral Science, vol. 2 , iss. 4.

Garbarino, E, Orveillon, G, Saveyn, HGM, Barthe, P \& Eder, P 2018, Best Available Techniques (BAT) Reference Document for the Management of Waste from Extractive Industries, in accordance with Directive 2006/21/EC, Publications Office of the European Union, Luxembourg, https://doi.org/10.2760/35297

Noy, MJ 2013, 'Automated rock fragmentation measurement with close range digital photogrammetry', in PK Singh \& A Sinha (eds), Measurement and Analysis of Blast Fragmentation: the 10th International Symposium on Rock Fragmentation by Blasting, CRC Press, Leiden.

Pearce, SR, Aktas, V \& Naithani, R 2014, 'Heterogeneity profiling: a technique to improve geochemical sampling and analysis for AMD assessments', in H Miller \& L Preuss (eds), Proceedings of the Eighth Australian Workshop on Acid and Metalliferous Drainage, pp. 295-312.

Pearce, SR, Beavis, FR, Winchester SJ \& Thompson, H 2012, 'Managing closure risks by integrating acid and metalliferous drainage studies with mine scheduling - real world examples', in AB Fourie \& M Tibbett (eds), Proceedings of the Seventh International Conference on Mine Closure, Australian Centre for Geomechanics, Perth, pp. 801-814.

Price, WA 2009, Prediction Manual for Drainage Chemistry from Sulphidic Geologic Materials: MEND Report 1.20.1, Natural Resources Canada, Ottawa.

Singh, PK, Roy, MP, Paswan, RK, Sarim, Md, Kumar, S \& Ranjan Jha, R 2016, 'Rock fragmentation control in opencast blasting', Journal of Rock Mechanics and Geotechnical Engineering, vol. 8, no. 2.

The International Network for Acid Prevention 2009, Global Acid Rock Drainage Guide (GARD Guide), http://www.gardguide.com 